[CONTRIBUTION FROM THE LABORATORY OF ANALYTICAL CHEMISTRY, UNIVERSITY OF MICHIGAX.]

\title{
DETERMINATION OF NICKEL IN NICKEL-STEEL.
}

BY E. D. CAMPIELL.

Received Dectuhler $25,1893$.

THE growing importance of nickel-steel has rendered it desirable to have a rapid and accurate method for the determination of nickel in that metal, since the value of the steel is largely dependent upon the amount of nickel which it contains.

The methods in use at present for the determination of comparatively small amounts of nickel in the presence of a large, amount of iron, and the separation of the nickel from the manganese and copper, with which it is in most cases associated in this steel, involves usually one or more basic acetate precipitations and the use of either hydrogen sulphide or of anmonium sulphide in the subsequent work.

On account of the strong tendency of the basic acetate of iron to retain nickel, and of the various objections to the use of hydrogen sulphide or of ammonium sulphide as a precipitant, it was thought desirable, if possible, to devise a method which should not be open to any of the above objections.

The following methods worked out with my assistance by Messrs. Richard Fischer and W. G. Wallace, will, I think, be found to be sufficiently accurate for technical work. As the result of a large number of experiments upon solutions of steel, to which had been added known amounts of nickel, manganese and copper, the last two being added in amounts varying from two to ten times that in which they would occur in nickel-steel, in order that any interference of these elements might be detected, it was found that the nickel could be accurately determined within $0.00 \mathrm{I}$ gram, the usual error not exceeding 0.0003 gram to 0.0005 gram. The amount of nickel recovered is usually a little higher than, the true anount, the increase being due to the solubility of ammonium manganous phosphate, the nnanganese of which accompanies the nickel in the subse- 
quent work. The principles involved in the processes below described are the following :

Ist. The iron is precipitated as ferric phosphate in cold, strong acetic acid solution, under which conditions it precipitates perfectly free from nickel, although retaining a small amount of copper.

2nd. The copper is separated from manganese and nickel in hydrochloric acid solation by means of granulated lead.

3td. The manganese and lead, which displaced the copper, are separated from the nickel by means of a cold ammoniacal solution of sodium phosphate.

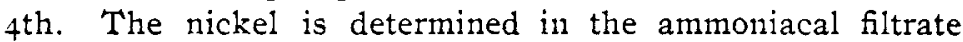
from the phosphate of manganese and lead, by titration with standard potassium cyanide or by electrolytic deposition.

In case the nickel is accompanied by cobalt the latter metal remains with the nickel, and may be separated from it by any of the well-known methods after dissolving off the electrolytically deposited nickel.

The two methods described below are identical up to the point where a portion of the filtrate from the phosphates of manganese and lead is taken. The description of that part of the methods common to both will be first given, and then the two ways of treating the above filtrate for the final determination of nickel will be detailed.

\section{DETAILS OF METHODS.}

Take 2.2222 grams nickel-steel, place in a $500 \mathrm{cc}$. graduated flask, add twenty cc. nitric acid, sp. gr. I.2O, and five cc. strong hydrochloric acid sp. gr. r.2I. Boil until the solution is clear, which will usually require not more than from five to ten minutes. Remove from the plate and add I $55 \mathrm{cc}$. sodium phosphate solution. If a slight precipitate should form which does not dissolve upon shaking, add carefully a few drops of hydrochloric acid until the solution clears up. Add twenty-five cc. strong acetic acid, sp. gr. I.O4 then I0O cc. sodium acetate solution, shake; dilute with water to $502.5 \mathrm{cc}$., shake again and allow to stand fifteen minutes. Filter through a dry, twentyfive $\mathrm{cm}$. filter, catching the filtrate in a dry beaker. As soon as 
enough of the filtrate has run through. which requires about ten minutes, draw off with a pipette $250 \mathrm{cc}$. of the filtrate, transferring to a number four beaker. This will give one-half of the solution, since it was found by experiment that the ferric pirosphate from the amount of steel taken occupies $2.5 \mathrm{cc}$. Bring the solutiont to a boil and add twenty grans potassium hydroxide previously dissolved in forty cc. of water. Boil five minutes, then keep just below boiling point until the precipitate has settled and the solution is clear. This precipitates copper, manganese, and nickel so completely that the filtrate gives no color with hydrogen sulphide. Filter through asbestos, using a pump, decanting as much of the solution as possible before allowing the precipitate to get upon the filter. Wash with water. Dissolve the precipitate on the filter in a hot solution of six cc. strong hydrochloric acid with an equal volume of water. Wash the filter using only as much water as is necessary To the solution in the flask, which should not exceed fifty cc. and should have a temperature of $40^{\circ}$ to $50^{\circ} \mathrm{C}$. add fifteen grams granulated lead and agitate at frequent intervals for five to ten minutes. This will completely precipitate the copper, a small amount of lead going into solution. Filter through a small glass wool filter, catching the filtrate in a number two beaker: wash the granulated lead with a small amount of water and boil the solution down until it does not exceed sixty cc. Add ten cc. of sodium phosphate solution, then anmonium hydroxide until a precipitate just forms, then hydrochloric acid until the solution just clears up, cool until cold, and transfer to a cylinder or flask graduated to I I I. I ce. Add five cc. strong ammonium hydroxide, sp. gr. 0.yo, dilute to the mark, shake well and allow to stand fifteen minutes. Filter through a dry nine cm. filter, receiring the filtrate into a dry beaker. Draw off, by means of a pipette. roo cc. of this filtrate which is equivalent to one gram of the original steel, and treat by one of the two following methods:

\section{ELECTROLYTIC METHOD.}

Transfer the $100 \mathrm{cc}$. of filtrate above mentioned to a large platinum dish having a capacity of about $200 \mathrm{cc}$. Add twenty- 
five cc. of strong ammonium hydroxide, sp. gr. 0.90 , and dilute to $75 \mathrm{cc}$. Electrolyze for at least four hours, preferably over night, using a current yielding four cc. of electrolytic gas per minute. This strength of current can be easily obtained by connecting three medium sized cells. A very satisfactory arrangement to avoid the excessive loss of ammonia and the spattering of the solution due to the active evolution of gas, is to cover the platinum dish with a large watch glass perforated in the center through which the positive electrode, consisting of a large platinum cone, is suspended by means of a platinum wire.

The end of the precipitation of the nickel is indicated when a drop of the solution placed upon a drop of ammonium sulphide gives no color due to nickel sulphide. When the nickel is completely precipitated, disconnect the battery, wash the nickel thoroughly with water, then finally twice with alcohol and, after draining off as much as possible, heat for a few minutes in an air-bath at $110^{\circ} \mathrm{C}$. Cool and weigh. After getting the combined weights of the platinum dish and nickel, dissolve off the latter by warming with $5-6 \mathrm{cc}$. of nitric acid, sp. gr. I.2O, then wash the platinum dish by means of water and alcohol and dry and weigh as before. The difference in the two weighings gives the nickel.

It is more satisfactory to weigh the empty dish after the precipitated nickel has been dissolved off than before electrolysis, since in this way a shorter time will elapse between the two weighings and consequently less error will be introduced from variations in atmospheric conditions. This latter source of error may be still further reduced by employing as a counterpoise for the platinum dish, upon which the nickel is precipitated, a similar platinum dish washed, dried and cooled under the same circumstances as the former.

\section{VOLUMETRIC METHOD.}

Take $100 \mathrm{cc}$. of the filtrate from the phosphate of manganese and lead, add hydrochloric acid very carefully until the blue color of the double ammonium nickel chloride disappears, then add ammonium hydroxide, drop by drop, until the blue just reappears and add an excess not exceeding one cc. Dilute to 200 
cc., add five cc. of cupric ferrocyanicie indicator and run in standard potassium cyanide until the solution turns from the purple color of the indicator to a periectly clear light straw yellow. Subtract from the number of cubic centimeters of potassium cyanide used the correction tor the indicator. The difference gives the anount necessary to convert the nickel into the double cyanicie of potassium ant nickel. Mutiplying this by the factor of the potassium cyanice, expressed in metallic nickel. gives the anount of nickel in one gram of the original sample.

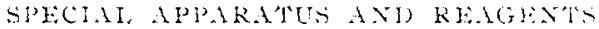

$500 \mathrm{cc}$ graduated flask with an additional mark at $502.5 \mathrm{cc}$. $250 \mathrm{cc}$. drop pipette. $100 \mathrm{cc}$ drop pipette.

Glass stoppered cylincler or flask graduated to rif.r cc. The graduated apparatus should be carefully calibrated and compared before using.

Sodium phosphate solution, made by dissolving 200 grams of the ordinary crystallized disodiuin hydrogen phosphate in 1860 cc. of water. Ten cc. of this solution contain one gram of the crystallized salt, and it requires serenty $\mathrm{cc}$, to precipitate one gram of iron as ferric phosplate.

Sodium acetate solution, made by dissolving 250 grams crystallized sodimm acetate in $820 \mathrm{cc}$. of water. Ioo cc. of this solution contain twenty-five grams of sodium acetate, which is a slight excess over that which is necessary to convert the nitric and hydrochloric acids to sodium nitrate and chloride, with the liberation of the corresponding amount of acetic acid.

Granulated lead is of the same quality as that used in assaying. In size it should be that which passes through a sieve with twenty meshes to the inch, but remains upon a sieve with forty meshes.

Before using, the lead should be washed with dilute hydrochloric acid (one part acid to two parts water) in order to dissolve any oxide that may be present.

Standard nickel solution. This may be made from chemically pure nickel by dissolving 2.5 grams nickel in fifty cc. nitric acid, sp. gr. I.20, adding an excess of hydrochloric acid, evaporating on a water-bath nearly to dryness, then diluting to I000 
cc., one cc. equals 0.0025 grams nickel. Or it may be made from chemically pure nickelous chloride by dissolving six grams in water with the addition of a few drops of hydrochloric acid, and diluting to rooo $\mathrm{cc}$. This latter solution must be standardized. In order to do this, take thirty cc., place in a large platinum dish, add twenty-five cc. of strong ammonium hydroxide, dilute to $175 \mathrm{cc}$. and electrolyze as in the electrolytic method for nickel.

Standard potassium cyanide solution. Take twelve grams of chemically pure potassium cyanide, dissolve in water, dilute to one liter. This must be standardized against a standard nickel solution. Since the presence of ammonium salts interferes somewhat in the titration with potassium cyanide, necessitating the use of a slightly greater amount of potassium cyanide than would be required if there were no ammonium salts present, it is better that the potassium cyanide be standardized under the same conditions as are met in analysis. To standardize the potassium cyanide, take $15-20 \mathrm{cc}$. of standard nickel solution, add six cc. of hydrochloric acid, sp. gr. 1.20, ten cc. sodium phosphate solution, amnonium hydroxide until the solution turns blue and then five $c c$. in excess. Now add hydrochloric acid until the blue color of the double nickel chloride disappears, then again ammonium hydroxide until the blue just reappears, and an excess not exceeding one cc. Dilute to $200 \mathrm{cc}$., add five cc. cupric ferrocyanide indicator, and run in potassium cyanide until the solution changes from the purplish color imparted by the indicator to a perfectly clear light straw yellow.

Divide the amount of nickrl in the standard nickel solution taken by the number of cubic centimeters of potassium cyanide used, less the correction for the indicator. The result will give the strength of the potassium cyanide expressed in metallic nickel.

Cupric ferrocyanide indicator. Take 2.5 grams of crystallized cupric sulphate, dissolve in twenty-five cc. of water, add to this a solution of ammonium oxalate until the precipitate first formed just redissolves, then dilute to $500 \mathrm{cc}$. Dissolve 2.5 grams of potassium ferrocyanide in $500 \mathrm{cc}$ of water, then slowly pour this solution into the cupric sulphate solution, stirring constantly 
during the operation. This will give a deep purplish brown solution of cupric ferrocyanide which may precipitate partially on standing; but the precipitate so formed will be so fine that it will easily remain in suspension for a long time, upon shaking the bottle, thus insuring uniform composition. To find the correction for the indicator take $200 \mathrm{cc}$. of water, add $6-8$ drops of ammonium hydroxide, then five cc. of indicator, taken after shaking the bottle well, and then run in potassium cyanide until the characteristic change of color is obtained.

Five cc. of cupric ferrocyanide of the above strength require from $0.15-0.2 \mathrm{cc}$. of potassium cyanide, one $\mathrm{cc}$. of which is equivalent to 0.0025 of nickel. If a stronger end reaction is desired, ten $c c$ or even fifteen $c c$. of the indicator may be used and a suitable correction made.

Repeated analyses of steel have shown that the nickel may be determined, by the volumetric method, within from 0.0003 to 0.0005 gram of the true nickel content, duplicate determinations being made in three hours. The electrolytic method requires three hours to the time the solution is ready for electrolysis.

AXN ARBOR, MICHEGAS,

DECEMRER 7 . I8, ?

\section{PRELIMINARY REPORT OF THE COMMITTEE ON THE TARIFF.}

THE COLUMBAN UNIVERSITY,

Washington, D. C., January I5, 1894.

H. W. Wiley, Ph.D., Etc., Etc.,

President American Chemical Society,

SiR:- Your favor of January 5, 1894, announcing the appointment of the Committee on the Tariff, with the undersigned as Chairman has been received, and while from the nature of the case, it has not been possible to call the committee together for action, steps have been taken to secure information upon which to base our action.

We learn that efforts are being made to try and settle the question "What are philosophical or scientific instruments and prepa- 